\title{
Effects of Ultrasonic Scaling at Different Power Settings on Surface Roughness of a Class V Composite Restorative Material: An in Vitro Study
}

\author{
Dr. Thangavel Boopathi ${ }^{1}$, Dr. Sekar Manimaran ${ }^{2 *}$, Dr. Mathew Sebeena ${ }^{3}$, Dr. Kumaravadivel Karthick ${ }^{1}$, Dr. Natesan \\ Thangaraj Deepa ${ }^{1}$
${ }^{1}$ M.D.S, Professor, Department of Conservative Dentistry and Endodontics, KSR Institute of Dental Science and Research, Tiruchengode, Namakkal (District), Tamilnadu- 637215, India
${ }^{2}$ B.D.S, PG Student, Department of Conservative Dentistry and Endodontics, KSR Institute of Dental Science and Research, Tiruchengode, Namakkal (District), Tamilnadu- 637215, India
${ }^{3}$ M.D.S, Professor and Head of the Department, Department of Conservative Dentistry and Endodontics, KSR Institute of Dental \\ Science and Research, Tiruchengode, Namakkal (District), Tamilnadu- 637215, India
}

Article History
Received: 22.12 .2021
Accepted: 30.01 .2022
Published: 04.02 .2022
Journal homepage:
https://www.easpublisher.com
Quick Response Code

\begin{abstract}
Aim: This study evaluated the effects of the ultrasonic scaling on the surface roughness of the restorative materials at different power settings. Materials and Methods: 48 specimens of rectangular recesses $(12 \times 8 \times 1.5 \mathrm{~mm})$ of Teflon molds were made, filled with a nanohybrid composite resin and cured. Pre-ultrasonic surface roughness was measured using Surface Roughness Tester. The specimens were divided randomly into 2 groups with each group consisting of 24 specimens. The group 1 and group 2 specimens were subjected under medium and high power setting ultrasonic scaling respectively. Postultrasonic surface roughness was measured as mentioned previously. Data were analysed with paired t-test and independent t-test. Results: Statistical analysis was done using SPSS software version 16.0. $\mathrm{P}<0.05$ was considered statistically significant. The results showed that surface roughness of the restorative material increased after ultrasonic instrumentation. Intergroup comparison revealed that post-ultrasonic surface roughness was more in the high power setting when compared to the medium power setting. Conclusion: It is recommended to use medium power setting ultrasonic scaling and to repolish the restorations to bring down the surface roughness to the clinically acceptable level.

Keywords: Class V restorations, Nanohybrid Composite, Surface roughness, Ultrasonic scaling, Power settings.
\end{abstract}

Copyright ( ) 2022 The Author(s): This is an open-access article distributed under the terms of the Creative Commons Attribution 4.0 International License (CC BY-NC 4.0) which permits unrestricted use, distribution, and reproduction in any medium for non-commercial use provided the original author and source are credited.

\section{INTRODUCTION}

Class V lesions are the defects that occurs on the gingival third of facial and lingual surfaces of all teeth, including the carious as well as Non-Carious Cervical Lesions (NCCLs) [1]. Problems associated with these lesions include micro leakage, postoperative sensitivity, difficulty in moisture control and isolation and lack of mechanical retention [2,3]. These lesions are more prone to the cuspal flexure due to the mechanical stresses of occlusal loading at the cervical margin resulting in higher failure rates. Hence, success of these restorations depends on the selection of the restorative materials $[4,5]$. The materials which are widely used to restore cervical lesions include conventional glass ionomer cements, composite resins and their combinations due to the esthetic concerns [6] Plaque and calculus deposits occur heavily in these regions leading to gingival irritation. These deposits make the dentist or dental hygienist unable to differentiate between the tooth and the tooth-colored restorations, therefore leading them to run the ultrasonic tip over the tooth as well as the restorations [7]. This in turn will increase the surface roughness, thereby contributing to plaque accumulation, escalating the risk of both caries and periodontal inflammation [8].

The surface roughness of various restorative materials are determined using profilometer or surface roughness tester. The surface roughness is usually represented by the parameter $\mathrm{Ra}$ (Average roughness).

*Corresponding Author: Dr. Sekar Manimaran

B.D.S, PG Student, Department of Conservative Dentistry and Endodontics, KSR Institute of Dental Science and Research,

Tiruchengode, Namakkal (District), Tamilnadu- 637215, India 
It is derived by calculating the arithmetic mean of the vertical departure of a profile from the mean $[2,9]$.

A review of the literature have unveiled that there are studies showed the effects of ultrasonic scaling at different power setting over the tooth surfaces but not regarding the restorative materials [10]. Hence the aim of this in vitro study was to determine the effects of ultrasonic scaling at different power settings over a nanohybrid composite resin, which is commonly used in class $\mathrm{V}$ lesions.

\section{Materials ANd Methods}

In this study, a nanohybrid composite (Tetric $\mathrm{N}$-CeramTM, Ivoclar Vivadent, India) was used. These materials were slightly overfilled into the rectangular recesses $(12 \times 8 \times 1.5 \mathrm{~mm})$ of customised Teflon molds and covered with matrix strips. A glass slide was placed over the molds and pressure was applied, causing the excess materials to extrude. These materials were then polymerized through the glass slide using a halogen light-curing unit (LEDition, Ivoclar Vivadent, Liechtenstein, USA) according to the manufacturer's instructions. 48 such specimens were prepared. All the specimens were rinsed in running tap water for 30 seconds. They were air dried.

The initial surface roughness of 48 specimens was evaluated in terms of Ra value (micrometers) using Surface Roughness Tester (Mitutoyo, Japan, SJ 210) with stylus moving at the speed of $0.5 \mathrm{~mm} / \mathrm{s}$. The specimens were divided into 2 groups based on power settings, with each group consisting 24 specimens. The group 1 and group 2 specimens were subjected under medium power setting (power mode $=6$ ) and high power setting (power mode $=12$ ) respectively.

Later, ultrasonic scaling was performed on all specimens with SATELLAC (P5 NEWTRON XS, ACETON EQUIPMENT, France) ultrasonic scaler having N1 insert under copious water flow for 60 seconds at level 6 power setting for specimens in group 1 and level 12 in group 2. The scaling tip was angled approximately to 15 degrees to the restoration surface. To avoid operator variations, all instrumentations were performed by one experienced periodontist. The specimens were rinsed in running tap water for 30 seconds. All specimens were air dried, and postultrasonic instrumentation roughness was then evaluated as mentioned previously. To evaluate the normality of the data obtained, Q-Q probability plot has been used before the comparison.

\section{STATISTICS}

Data were analysed using SPSS version 16.0 (SPSS-Inc, Chicago, IL, USA). P $<0.05$ is considered statistically significant. Comparison of mean surface roughness values of two groups individually before and after ultrasonic scaling was done using the paired t-test. Intergroup comparison of increased surface roughness was done using independent t-test.

\section{RESULTS}

The mean surface roughness values $(\mathrm{Ra}$, in $\mu \mathrm{m})$ of each specimen of both the groups measured before and after ultrasonic instrumentation are represented in Figure 1.

The statistical results of comparison within and between the groups are represented in Table 1.

Paired t-test showed that ultrasonic instrumentation resulted in significant increase in surface roughness of all the specimens in group 1 and 2 with $\mathrm{P}$-values of $\mathrm{P} \sim 0.034 *$ and $\mathrm{P} \sim 0.001 *$ respectively.

Intergroup comparison was made using Independent t-test. Between group comparison showed significant difference ( $\mathrm{P} \sim 0.008)$. This implies that surface roughness increases more with the high power setting than that of medium power setting.

Table 1: Results of comparison within and between the groups

\begin{tabular}{|c|c|c|c|c|c|c|c|}
\hline & & Mean & $\mathbf{N}$ & $\begin{array}{l}\text { Std. } \\
\text { Deviation }\end{array}$ & $\begin{array}{l}\text { Std. Error } \\
\text { Mean }\end{array}$ & $\begin{array}{l}\text { Paired ' } t \text { ' } \\
\text { test }\end{array}$ & $\begin{array}{l}\text { Independent ' } t \text { ' } \\
\text { test }\end{array}$ \\
\hline \multirow[t]{2}{*}{$\begin{array}{l}\text { Group } \\
1\end{array}$} & $\begin{array}{l}\text { Initial } \\
\text { Roughness }\end{array}$ & 0.72 & 24 & 0.413 & 0.084 & \multirow[t]{2}{*}{$0.034 *$} & \multirow[t]{4}{*}{$0.008 *$} \\
\hline & After Scaling & 1.65 & 24 & 0.435 & 0.089 & & \\
\hline \multirow[t]{2}{*}{$\begin{array}{l}\text { Group } \\
2\end{array}$} & $\begin{array}{l}\text { Initial } \\
\text { Roughness }\end{array}$ & 0.76 & 24 & 0.492 & 0.100 & \multirow[t]{2}{*}{$0.001 *$} & \\
\hline & After Scaling & 2.36 & 24 & 0.899 & 0.184 & & \\
\hline
\end{tabular}




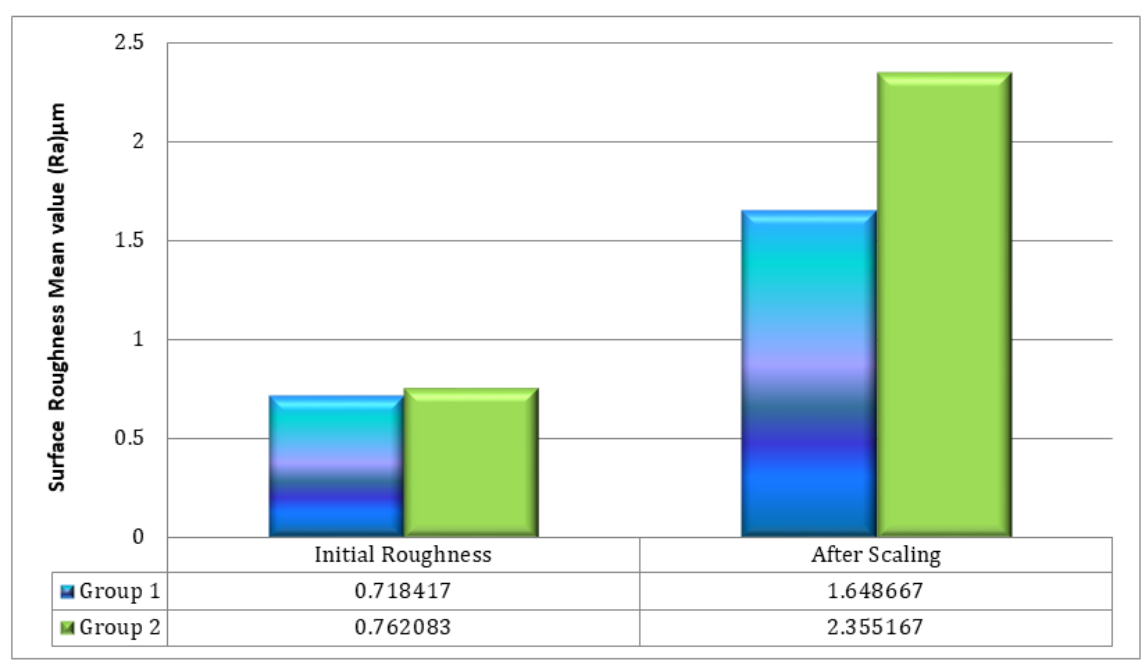

Figure 1: Graphical representation of the mean score of surface roughness of two groups

\section{DISCUSSION}

The causes of class $\mathrm{V}$ caries include uncleaned tooth surface, caries inducing diet, gingival recession, reduced salivary flow due to medications, head and neck radiation therapy or certain medical conditions. The materials restoring such defects should possess the properties like strength, longevity, ease of use, esthetics, ability to bond to tooth structure, good finishing and polishing [9]. The materials having the above mentioned properties are glass ionomer cement, composite. Glass ionomers are more prone to surface alterations than resin based composites [11].

The composite resin bond to the dentin by the formation of hybrid layer [12]. The commonly used dental composites are hybrid and microfill types. The hybrid composites are incorporated with filler of particle size ranging from 15-20 microns and 0.010.05microns. They offer intermediate esthetics but excellent mechanical properties. Microfill composites were introduced to provide good esthetics. But they provide low mechanical properties to use in the regions of high occlusal load [12, 13]. To overcome these problems, new classes of dental composites, so called nanocomposites have been introduced [13].

Nanohybrid composites intermingle the mechanical strength of hybrid composites and superior esthetics of microfill composites [14]. It has many desired properties like decreased polymerization shrinkage, good optical characteristics, better gloss retention, and diminished wear due to the decreased difference in size of polymer matrix and filler particles and increased filler content [14-16].

Tetric N-Ceram is a type of methacrylate based nanohybrid composite [17]. It contains ytterbium trifluoride with particle size ranging from $20-40 \mathrm{~nm}$ [18].
The plaque and calculus deposits occur all around the teeth, especially in the cervical region. This is encountered by scaling either with hand or machine driven instruments. Sonic and ultrasonic scaling are becoming very popular among the dentists due to the decreased time requirement and ease of application, associated flow of water which not only cools the tip and but also clear the site of debris and improve the field of vision during the procedure [10, 19].

However, they might cause scratches, nicks, and chips on the tooth and the restorations, thereby increasing the surface roughness of tooth as well as the restorations $[11,19,20]$. The increased surface roughness of the composite resin may be attributed to the preferential removal of weak matrix, thereby leaving the harder unreacted glass or filler particles protruding from the surface [21, 22]. The increased surface roughness in turn increases the available surface area 2 to 3 times, providing niche for attachment and growth of the microorganisms, thereby causing quicker plaque accumulation and difficult plaque removal [8, 23]. The surface roughness above 0.2 microns and 0.5 microns causes increased plaque accumulation and patient discomfort respectively. The former stated by Bollen et al., and the latter by Jones et al., [24, 25].

It has been well demonstrated that ultrasonic scaling increases the surface roughness, when operated at both high as well as medium power settings. Within the limitations of this study, it has been proved that the surface roughness increases much more in high power setting than at medium power setting. Not only the surface roughness, it has also been showed in other studies that medium power setting is beneficial than the high power setting, which is discussed below.

The acoustic power output is usually measured with the displacement amplitude of the scaler tip [26]. It measures the chipping action of the tip as well as the amount of cavitational activity produced within the 
irrigation solution. The magnitude of this oscillation can be altered by a control dial [10].

The ultrasonic scaler was equally effective when operated at half power or full power. However, working at high setting for a long time may produce potential aerosol hazard and thermal damage. A low to medium power setting produce adequate chipping action and also reduced aerosol formation. The amount of cavitational activity generated were sufficient to remove the plaque and bacterial endotoxin adequately $[10,27,28]$. At half power it retains more water thereby giving protection against the mechanical or thermal root surface damage and increases therapeutic effectiveness [10].

Erdilek et al., have proved in their study that repolishing decreases the surface roughness of all the materials to their baseline level [29]. Therefore, repolishing the scaled surfaces is mandatory to prevent the secondary caries, surface staining, plaque accumulation and subsequent periodontal inflammation.

\section{CONCLUSION}

Within in the limitations of this study it can be concluded that,

- Ultrasonic scaling increases the surface roughness of the restorative materials.

- Higher the power setting more will be the postultrasonic surface roughness of the restorative material.

- It is recommended to use ultrasonic scaling at medium power setting on the surface of the restorations.

- Repolishing of the restoration is advised to decrease the surface roughness to the clinically acceptable level.

\section{ACKNOWLEDGEMENTS}

I acknowledge my staffs, seniors and institution for their support in completing this study and manuscript.

\section{REFERENCES}

1. Roberson, T. M. (2010). Fundamentals in tooth preparation. In: Robertson, T. M., Heymann H. O., \& Swift, E. J., editors. Sturdevant's Art and Science of operative Dentistry. 5th ed. Haryana (India): Elsevier; p. 281-324.

2. Francisconi, L. F., Scaffa, P. M. C., Barros, V. R. D. S. P. D., Coutinho, M., \& Francisconi, P. A. S. (2009). Glass ionomer cements and their role in the restoration of non-carious cervical lesions. Journal of Applied Oral Science, 17, 364-369.

3. Jyothi, K. N., Annapurna, S., Kumar, A. S., Venugopal, P., \& Jayashankara, C. M. (2011). Clinical evaluation of giomer-and resin-modified glass ionomer cement in class $\mathrm{V}$ noncarious cervical lesions: An in vivo study. Journal of conservative dentistry: JCD, 14(4), 409-113.

4. Ichim, I. P., Schmidlin, P. R., Li, Q., Kieser, J. A., \& Swain, M. V. (2007). Restoration of non-carious cervical lesions: Part II. Restorative material selection to minimise fracture. dental materials, 23(12), 1562-1569.

5. Vasudeva, G., Bogra, P., Nikhil, V., \& Singh, V. (2011). Effect of occlusal restoration on stresses around class V restoration interface: A finiteelement study. Indian Journal of Dental Research, 22(2), 295-302.

6. Burrow, M. F., \& Tyas, M. J. (2007). Clinical evaluation of three adhesive systems for the restoration of non-carious cervical lesions. Operative dentistry, 32(1), 11-15.

7. Shenoi, P. R., Badole, G. P., Khode, R. T., Morey, E. S., \& Singare, P. G. (2014). Evaluation of effect of ultrasonic scaling on surface roughness of four different tooth-colored class V restorations: An invitro study. Journal of conservative dentistry: JCD , 17(5), 471-475.

8. Teughels, W., Van Assche, N., Sliepen, I., \& Quirynen, M. (2006). Effect of material characteristics and/or surface topography on biofilm development. Clinical oral implants research, 17(S2), 68-81.

9. Roberson, T. M., Heymann, H. O., Ritter, A. V., Pereira, P. N., \& Wilder, A. D. (2010). Class III, IV and $\mathrm{V}$ composites and other tooth-colored restorations, class III and class $\mathrm{V}$ restorations. In: Roberson, T. M., Heymann, H. O., Swift, E. J., editors. Sturdevant's Art and Science of Operative Dentistry. 5th ed. Haryana, India: Elsevier; p. 527566, 783-806.

10. Vaid, D. S., Shah, N. C., \& Bilgi, P. S. (2015). One year comparative clinical evaluation of EQUIA with resin-modified glass ionomer and a nanohybrid composite in noncarious cervical lesions. Journal of conservative dentistry: JCD, 18(6), 449-452.

11. Sideridou, I. D., Karabela, M. M., \& Vouvoudi, E. C. (2011). Physical properties of current dental nanohybrid and nanofill light-cured resin composites. Dental materials, 27(6), 598-607.

12. Jung, M., Bruegger, H., \& Klimek, J. (2003). Surface geometry of three packable and one hybrid composite after polishing. Operative dentistry, 28(6), 816-824.

13. Jung, M., Sehr, K., \& Klimek, J. (2007). Surface texture of four nanofilled and one hybrid composite after finishing. Operative Dentistry, 32(1), 45-52.

14. Jung, M., Eichelberger, K., \& Klimek, J. (2007). Surface geometry of four nanofiller and one hybrid composite after one-step and multiple-step polishing. Operative Dentistry, 32(4), 347-355.

15. Sood, A., \& Sathyanarayanan Ramarao, U. C. (2015). Influence of different crosshead speeds on diametral tensile strength of a methacrylate based 
resin composite: An in-vitro study. Journal of conservative dentistry: JCD, 18(3), 214-217.

16. Sapra, V., Taneja, S., \& Kumar, M. (2013). Surface geometry of various nanofiller composites using different polishing systems: A comparative study. Journal of conservative dentistry: $J C D, 16(6), 559-563$.

17. Mourouzis, P., Koulaouzidou, E. A., Vassiliadis, L., \& Helvatjoglu-Antoniades, M. (2009). Effects of sonic scaling on the surface roughness of restorative materials. Journal of Oral Science, 51(4), 607-614.

18. Chapple, I. L., Walmsley, A. D., Saxby, M. S., \& Moscrop, H. (1995). Effect of instrument power setting during ultrasonic scaling upon treatment outcome. Journal of periodontology, 66(9), 756760.

19. Lai, Y. L., Lin, Y. C., Chang, C. S., \& Lee, S. Y. (2007). Effects of sonic and ultrasonic scaling on the surface roughness of tooth-colored restorative materials for cervical lesions. Operative dentistry, 32(3), 273-278.

20. Hossam, A. E., Rafi, A. T., Ahmed, A. S., \& Sumanth, P. C. (2013). Surface topography of composite restorative materials following ultrasonic scaling and its Impact on bacterial plaque accumulation. An in-vitro SEM study. Journal of international oral health: JIOH, 5(3), 13-19.

21. Gladys, S., Van Meerbeek, B., Braem, M., Lambrechts, P., \& Vanherle, G. (1997). Comparative physico-mechanical characterization of new hybrid restorative materials with conventional glass-ionomer and resin composite restorative materials. Journal of Dental Research, 76(4), 883-894.

22. Folwaczny, M., Loher, C., Mehl, A., Kunzelmann, K. H., \& Hinkel, R. (2000). Tooth-colored filling materials for the restoration of cervical lesions: a 24-month follow-up study. Operative dentistry, 25(4), 251-258.

23. Quirynen, M., Marechal, M., Busscher, H. J., Weerkamp, A. H., Darius, P. L., \& van Steenberghe, D. (1990). The influence of surface free energy and surface roughness on early plaque formation: an in vivo study in man. Journal of clinical periodontology, 17(3), 138-144.

24. Bollen, C. M., Papaioanno, W., Van Eldere, J., Schepers, E., Quirynen, M., \& Van Steenberghe, D. (1996). The influence of abutment surface roughness on plaque accumulation and peri-implant mucositis. Clinical oral implants research,7(3), 201-211.

25. Jones, C. S., Billington, R. W., \& Pearson, G. J. (2004). The in vivo perception of roughness of restorations. British dental journal, 196(1), 42-45.

26. Walmsley, A. D., Laird, W. R. E., \& Williams, A. R. (1986). Displacement amplitude as a measure of the acoustic output of ultrasonic scalers. Dental Materials, 2(3), 97-100.

27. Walmsley, A. D., Laird, W. R. E., \& Williams, A. R. (1988). Dental plaque removal by cavitational activity during ultrasonic scaling. Journal of clinical periodontology, 15(9), 539-543.

28. Smart, G. J., Wilson, M., Davies, E. H., \& Kieser, J. B. (1990). The assessment of ultrasonic root surface debridement by determination of residual endotoxin levels. Journal of clinical periodontology, 17(3), 174-178.

29. Erdilek, D., Sişmanoglu, S., Gumustas, B., \& Efes, B. G. (2015). Effects of ultrasonic and sonic scaling on surfaces of tooth-colored restorative materials: An in vitro study. Nigerian journal of clinical practice, 18(4), 467-471.

Cite This Article: Dr. Thangavel Boopathi, Dr. Sekar Manimaran, Dr. Mathew Sebeena, Dr. Kumaravadivel Karthick, Dr. Natesan Thangaraj Deepa (2022). Effects of Ultrasonic Scaling At Different Power Settings on Surface Roughness of a Class V Composite Restorative Material: An in Vitro Study. EAS J Dent Oral Med, 4(1), 7-11. 